\title{
Quistes hidatídicos recurrentes en la cavidad abdominal: reporte de un caso
}

\author{
Recurring hydatide cyst in abdominal cavity. A case report
}

\section{Salvador Moreno-Galeana*, Víctor S. Mora-Muñoz, Jorge Marmolejo-Estrada y Erick Servín-Torres}

Servicio de Cirugía General, Hospital de Especialidades Antonio Fraga Mouret del Centro Médico Nacional la Raza, Instituto Mexicano del Seguro Social, Ciudad de México, México

\section{Resumen}

El quiste hidatídico (hidatidosis o equinococosis) es una zoonosis endémica causada por la ingesta de huevos de Echinococcus. Esta enfermedad se localiza en el hígado, pero también puede encontrarse en otros sitios. Puede ser asintomática o presentarse con molestias por compresión o choque anafiláctico por rotura del quiste. Puede tener recurrencias. El diagnóstico se realiza por los síntomas y los hallazgos en imagenología. En ocasiones se realizan pruebas serológicas. El diagnóstico se confirma con la observación directa del parásito. El tratamiento es una combinación de antihelmíntico con drenaje mínimamente invasivo o quirúrgico. Se reporta el caso de una paciente con quistes hidatídicos recurrentes en el abdomen.

Palabras clave: Echinococcus. Enfermedad recurrente. Cirugía. PAIR. Quiste hidatídico. Equinococosis.

\begin{abstract}
Hydatid cyst (hydatidosis or echinococcosis) is an endemic zoonosis caused by ingestion of Echinococcus eggs. This disease is localized to the liver, but can be found elsewhere. It may be asymptomatic or present with compression discomfort or anaphylactic shock due to cyst rupture. The disease can recur. The diagnosis is made by the symptoms and imaging findings. Serological tests are sometimes done. The diagnosis is confirmed with direct observation of the parasite. Treatment is a combination of anthelmintic with minimally invasive or surgical drainage. This report is from a patient with recurrent hydatid cysts in the abdomen.
\end{abstract}

Key words: Echinococcus. Recurrent disease. Surgery. PAIR. Hydatid cyst. Echinococcosis.

\section{Introducción}

El quiste hidatídico, también referido como hidatidosis o equinococosis, es una zoonosis ocasionada por la ingesta de alimentos contaminados con los huevos de un parásito del género Echinococcus, perteneciente a la clase Cestoda y al filo Platyhelminthes. En el último consenso de 2020 , se clasifica en tres tipos: equinococosis quística (Echinococcus granulosus, la más común, con el $95 \%$ de todos los

\section{Correspondencia:}

*Salvador Moreno-Galeana

Calle 8 , número exterior 119 , número interior 5

Azcapotzalco

Fecha de recepción: 05-02-2021

C.P. 02990, Ciudad de México, México

E-mail: dr.salvadormorenogaleana@gmail.com
Fecha de aceptación: 09-02-2021

DOI: $10.24875 / \mathrm{CIRU} .21000107$
Cir Cir. 2021;89(S2):45-58

Contents available at PubMed www.cirugiaycirujanos.com

0009-7411/C 2021 Academia Mexicana de Cirugía. Publicado por Permanyer. Este es un artículo open access bajo la licencia CC BY-NC-ND (http://creativecommons.org/licenses/by-nc-nd/4.0/). 
casos), equinococosis alveolar (Echinococcus multilocularis) y equinococosis neotropical (Echinococcus vogeli o Echinococcus oligarthra) ${ }^{1}$. También durante este consenso se reconocieron nueve especies de Echinococcus, la restricción del adjetivo «hidatido» a E. granulosus sensu lato y la propuesta AORC (Approach, Opening, Resection, Completeness) para describir las intervenciones quirúrgicas en la equinococosis quística'.

A continuación se presenta un caso de enfermedad recurrente.

\section{Caso clínico}

Mujer de 38 años que fue referida al Hospital de Especialidades del Centro Médico Nacional La Raza, en Ciudad de México, en agosto de 2020, por presentar un quiste simple en el epigastrio y el mesogastrio con un volumen de $1288 \mathrm{ml}$. La paciente siempre ha vivido en una zona urbana y niega viajar a zonas rurales o agrícolas, convivencia con perros, asistencia a campamentos, cacería o falta de higiene en los alimentos. Dentro de sus antecedentes patológicos solo se encuentra tabaquismo durante 15 años a razón de un cigarrillo por día, suspendido hace 5 años, y consumo de alcohol ocasional sin llegar a la embriaguez. Como antecedentes quirúrgicos, tuvo una resección de un quiste hidatídico en 2001, durante la cual presentó fuga de líquido que le precipitó una reacción anafiláctica, y no recuerda tratamiento tras la resección. En 2015 tuvo una cesárea urgente por sufrimiento fetal. Inició su padecimiento actual en 2019 con dolor abdominal de tipo cólico, ocasional, de intensidad leve, el cual incrementó en frecuencia llegando a ser cotidiano e interferir con sus actividades habituales. Como síntoma acompañante refiere distensión abdominal posprandial. Niega durante la evolución del cuadro clínico náuseas, vómitos, fiebre, diarrea o pérdida de peso. En la exploración física no presentaba ictericia, se observaba el abdomen distendido y se palpaban dos tumores en ambos hipocondrios, poco móviles, de consistencia firme y bordes regulares. Se le realizó una tomografía computarizada (TC) abdominal que reportó imágenes quísticas en la pared abdominal y en el peritoneo parietal posterior compatibles con quistes hidatídicos (Fig. 1).

Se realizó planeación perioperatoria. La paciente tomó albendazol los 7 días previos a la cirugía (400 mg/12 h por vía oral) y poco antes de la operación recibió tratamiento con difenhidramina e

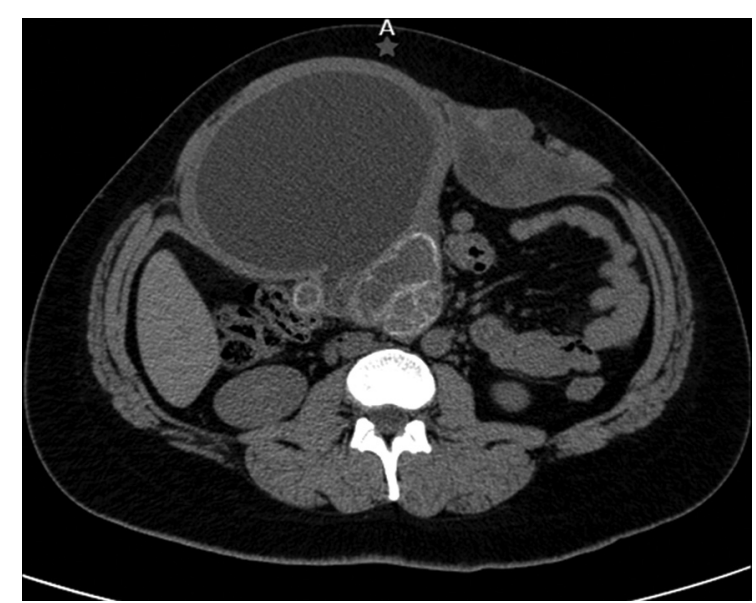

Figura 1. Imagen tomográfica en fase simple, corte axial, de la paciente con quistes hidatídicos. Se pueden observar múltiples quistes en distintas fases de la enfermedad: CE1, CE2 y C5. (Imagen obtenida del sistema del Centro Médico Nacional La Raza.)

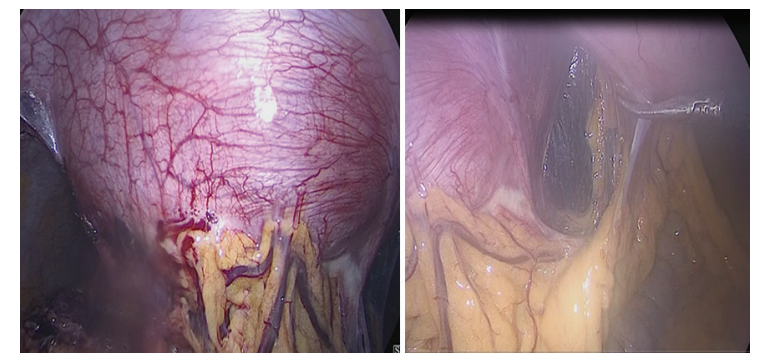

Figura 2. Imagen laparoscópica de los quistes hidatídicos. (Imágenes de los autores.)

hidrocortisona. La técnica quirúrgica para la extirpación de los quistes hidatídicos fue la siguiente (Fig. 2): se realizó abordaje laparoscópico, previa asepsia y antisepsia de la región abdominal, se insertó un trocar infraumbilical de $10 \mathrm{~mm}$ por medio de técnica de Hasson y se realizó neumoperitoneo con $\mathrm{CO}_{2}$ hasta una presión de $14 \mathrm{mmHg}$. Se observó un tumor quístico en la pared anterior abdominal de $14 \times 14 \times 13 \mathrm{~cm}$, subcostal derecho, así como múltiples adherencias asa-asa, asa-pared y asa-quiste, las cuales se liberaron con disección roma y electrocauterio (Zuhlke II, III). Se encontró otro quiste subcostal izquierdo de 7 $\times 5 \times 5 \mathrm{~cm}$, multilobulado. Alejados de estos quistes se colocaron dos trocares de 12 y $5 \mathrm{~mm}$. Se empezó a disecar el quiste de mayor tamaño con cauterio armónico, encontrándolo infiltrado hacia la pared abdominal e incluyendo el peritoneo parietal, la fascia posterior, el músculo recto del abdomen y la fascia anterior. Se extrajo parte del quiste por endobag 
(Fig. 3). Se resecaron otros dos quistes localizados en el epiplón, de $5 \times 5 \times 5 \mathrm{~cm}$. Posteriormente se localizó un quiste adyacente a los segmentos hepáticos III y IV, de $5 \times 5 \times 3 \mathrm{~cm}$; sin embargo, durante la disección de este se presentó una hemorragia difícil de controlar por laparoscopia, por lo que se decidió la conversión a cirugía abierta. Se realizó el abordaje en la línea media supra-infraumbilical, se identificó el vaso sangrante y se colocó un punto en $X$ con seda 2-0, con lo cual se logró la hemostasia. Se completó la exéresis del quiste. Se terminó también la exéresis de los quistes subcostal derecho y subcostal izquierdo multilobulado, de $7 \times 5 \times 5 \mathrm{~cm}$, incluyendo una resección parcial de peritoneo parietal anterior, fascia posterior, músculo recto abdominal y fascia anterior (resección en bloque). Se corroboró la hemostasia y se colocó un drenaje tipo Saratoga dirigido al lecho hepático y exteriorizado en el orificio del trocar de la región subcostal izquierda. Se cerró parcialmente la aponeurosis con sutura de poliglactina 910 del 1, se reportó tejido de mala calidad con alto riesgo de herniación. Se llevó a cabo el cierre del tejido celular subcutáneo con sutura de poliglactina 910 del 3-0, y de la piel con grapas quirúrgicas. El drenaje se fijó con monofilamento no absorbible del 2-0.

Durante el perioperatorio no se observaron reacción anafiláctica ni datos de choque. Sin embargo, en el posoperatorio se cuantificó una hemorragia de $1300 \mathrm{ml}$. Se transfundió un paquete globular, sin reacción aparente. La paciente cursó con adecuada evolución clínica posquirúrgica inmediata. Se inició dieta líquida a las 48 horas, con adecuada tolerancia, por lo que se progresó a dieta blanda. Se mantuvo afebril. Después de 2 días presentó atelectasia, la cual se resolvió sin eventualidades. Se egresó a los 5 días de la cirugía. Actualmente se mantiene en vigilancia y seguimiento, y continúa con albendazol (400 mg/12 h) por 12 meses con seguimiento trimestral.

El diagnóstico se confirmó con examen al microscopio directo en fresco del líquido del quiste y por estudio histopatológico (Figs. 4-5).

\section{Discusión}

\section{Agente causal, ciclo biológico y respuesta inmunitaria}

E. granulosus se consideraba una sola especie, pero gracias los avances en biología molecular ahora se describen distintas cepas o genotipos que
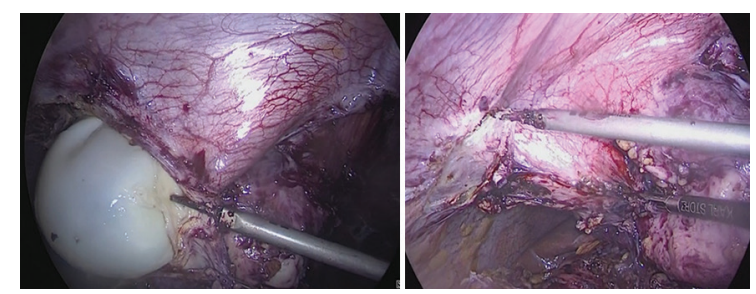

Figura 3. Disección de quiste y exposición. (Imágenes de los autores.)

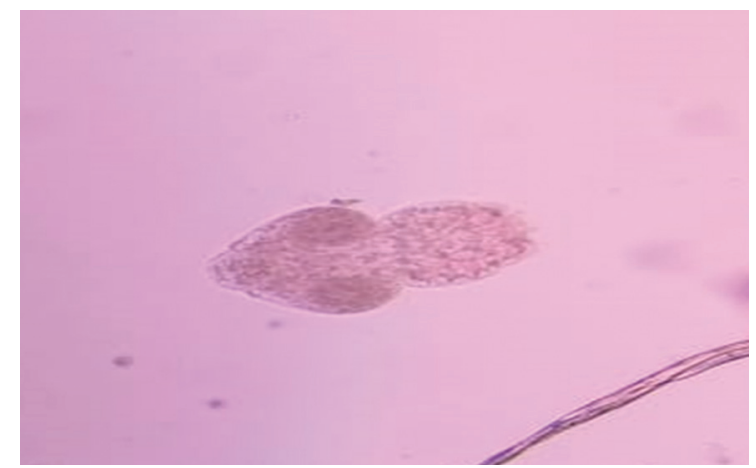

Figura 4. Imagen del protoescólex observado directamente en el microscopio óptico de la muestra del líquido del quiste de la paciente, que confirma el diagnóstico de equinococosis. (Imagen obtenida con permiso del departamento de parasitología del Hospital de Especialidades del Centro Médico Nacional La Raza.)

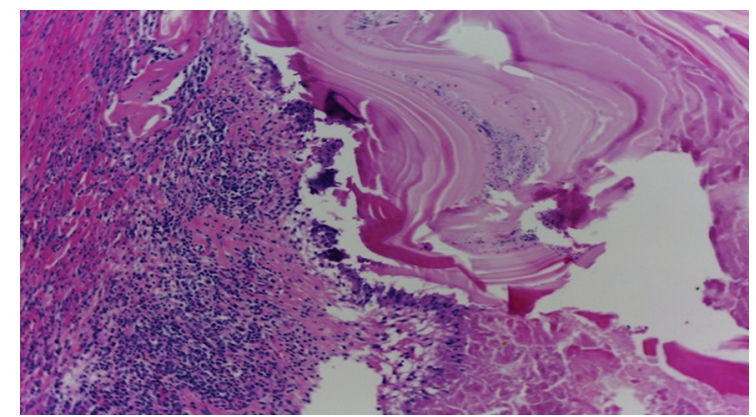

Figura 5. Corte histológico de quiste hidatídico, tinción con hematoxilina-eosina, $40 \times$. Se observa una importante reacción inflamatoria periquística, con infiltración importante de mononucleares, células gigantes. El líquido coloidal del quiste se tiñe con eosina. Se aprecia infiltración de células inflamatorias al interior del quiste. (Imagen obtenida con permiso del departamento de patología del Centro Médico Nacional La Raza.)

presentan diferencias en cuanto a patología y respuesta a fármacos y a la vacuna recombinante EG95 para ovinos ${ }^{2}$. La secuenciación del ADN mitocondrial permite reconocer diez genotipos (G1 a G10). La especie $E$. granulosus sensu lato se ha dividido en cinco especies: E. granulosus sensu stricto (la antigua cepa 

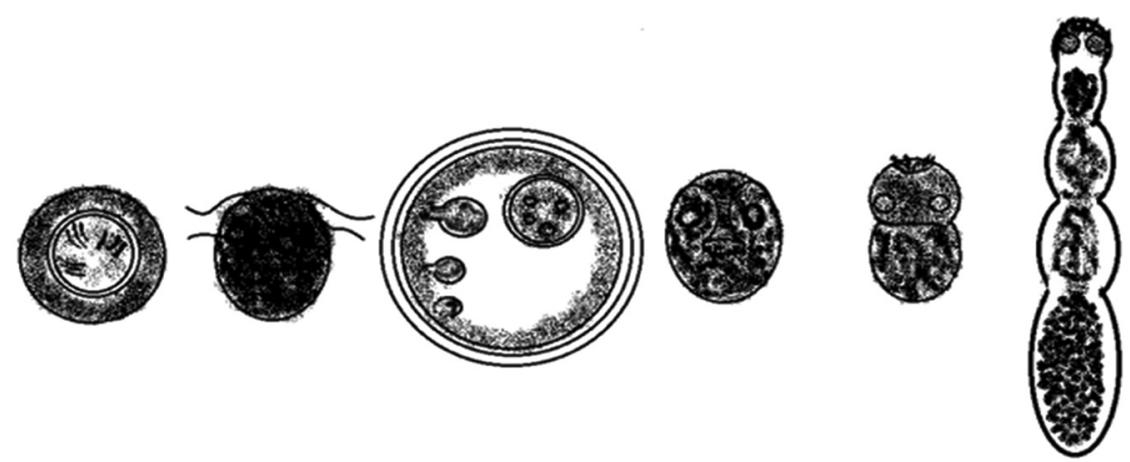

Figura 6. Diferentes estadios del parásito. De izquierda a derecha: huevo, oncosfera, quiste hidatídico, protoescólice, protoescólex y forma adulta del parásito. (Imagen de los autores.)

de oveja, G1 a G3), Echinococcus equinus (cepa de caballo, G4), Echinococcus ortleppi (cepa bovina, G5), Echinococcus canadensis (cepa de camello, G6; cepa de cerdo, G7; G9, probablemente una variante de la cepa de cerdo; y cepas de cérvidos, G8 y G10) y Echinococcus felidis (cepa de león)². E. granulosus sensu stricto es el de más amplia distribución². Muy probablemente nuestro caso clínico fue de por $E$. granulosus sensu stricto dados los antecedentes de la paciente; sin embargo, como no contamos en nuestro medio con estudios de biología molecular solo se diagnosticó Echinococcus sp.

El parásito tiene seis formas: forma adulta (etapa estrobilar, el gusano mide 3-6 mm), huevo, oncosfera, quiste hidatídico que origina los metacestodos (protoescólices o protoscoleces), y estos, al salir del quiste, se denominan protoescólex ${ }^{3}$ (Fig. 6). El parásito adulto cuenta con una cabeza o escólex que contiene cuatro ventosas, un rostellum (corona de ganchos para fijarse al intestino) y un cuello que posteriormente se continúa con tres o cinco proglótidos, de los cuales el ligado al cuello recibe el nombre de proglótido inmaduro, seguido del maduro y por último del gravídico. En los proglótidos se realizan la fecundación y la maduración de los huevos (el gusano es hermafrodita y realiza reproducción sexual). Los equinococos también se pueden reproducir asexualmente en la fase de quiste hidatídico por división celular y diferenciación en la capa germinal ${ }^{4}$. La forma adulta habita en el intestino delgado de sus hospederos definitivos (perros, lobos, felinos salvajes, gatos, mapaches zorros y coyotes) ${ }^{3}$. Sobrevive en el intestino gracias a que secreta inhibidores de las serina proteasas (serpinas) que contrarrestan los efectos potencialmente letales de las proteasas intestinales ${ }^{5}$. Se alimenta a través de su cutícula de péptidos, aminoácidos, hidratos de carbono, lípidos, vitaminas y minerales, provocando desnutrición y diarrea. Sin embargo, aun en hospederos asintomáticos se evacúan los huevos ${ }^{3}$.

El ciclo biológico (Fig. 7) comienza con la liberación en las heces de proglótidos grávidos que contienen huevos infectantes. Estos son depositados en un ambiente húmedo y templado, sobre pastizales o cerca de ríos, donde su hospedador intermediario, como las ovejas, las cabras, las vacas, los cerdos, los búfalos, los caballos, los ratones, los camellos o los humanos los ingieren. Los huevos pueden permanecer viables en el ambiente de semanas a meses, dependiendo de las condiciones de humedad y temperatura ${ }^{3}$. En el intestino de los hospederos intermediarios el huevo eclosiona, gracias a la acción de las enzimas digestivas y de la bilis, y libera la siguiente forma, llamada oncosfera. En esta fase, el parásito pasa a través de la capa mucosa y submucosa del intestino, y por medio de la circulación portal se localiza principalmente en el lóbulo derecho del hígado; sin embargo, puede migrar hacia otras localizaciones, como el meso, los pulmones, el cerebro, el hueso y muchas más ${ }^{4}$. En dichos sitios, las oncosferas se transforman en un quiste hidatídico $0^{4,5}$.

Las oncosferas liberan a su paso distintas proteínas, como la proteína $B(E g A g B)$ que es un componente crucial en el metabolismo de los lípidos, la proteína 5 (EgAg5) que participa en el metabolismo de las proteínas y un grupo de proteínas de la familia Kunitz que son inhibidoras de las serina proteasas ${ }^{6}$. Con estas proteínas el parásito de adapta en el microambiente y le ayudan a evadir el sistema inmunitario inactivando la inmunidad innata. Por ejemplo, la proteína denominada Eg95, que se localiza en la superficie del parásito, es un inhibidor del complemento. 


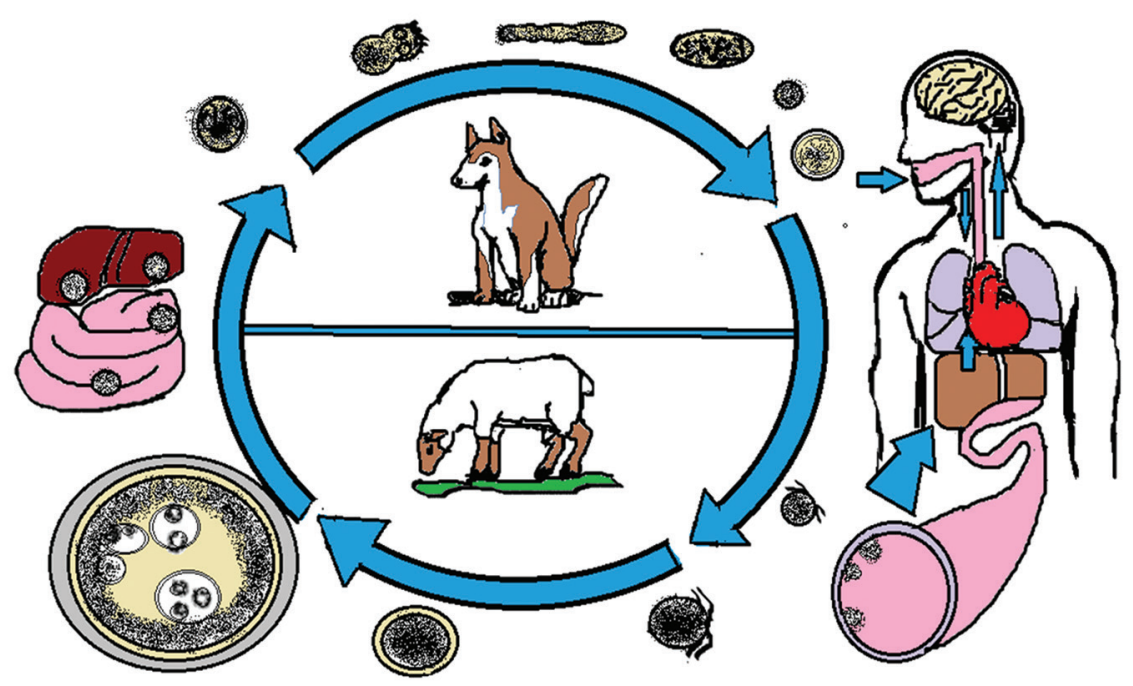

Figura 7. Ciclo biológico de Echinococcus. La forma adulta del parásito vive en el intestino delgado en sus hospederos definitivos, como los perros, los zorros o los coyotes, y ahí produce huevos que se excretan con las heces, de las que el hombre (hospedero accidental) o su hospedero intermediario (como las ovejas) adquieren la infección. El huevo libera una oncosfera que posteriormente atraviesa el intestino para localizarse en el hígado o migrar a otras localizaciones. Esta forma dará origen a los quistes hidatídicos, y estos a los protoescólices, y estos a los protoescólex infectantes que adquiere el hospedero definitivo al ingerir carne o vísceras contaminadas con este parasito, y que en su intestino darán nuevamente formas adultas y se iniciará otra vez el ciclo. (Imagen de los autores.)

Otro componente son los nanodepósitos de la sal cálcica del inositol hexakisfosfato (InsP6), que se encuentran en la capa de mucina del parásito y que inhiben C1q. Y otra proteína es el factor $\mathrm{H}$, que inhibe la vía alternativa de activación del complemento ${ }^{6}$.

Las oncosferas se implantan en los tejidos y dan origen a una capa germinal y una capa laminada (capa acelular) ${ }^{4,6}$. La capa germinal contiene células embrionarias que generan protoscoleces, que son la forma preinfectante del parasito y se identifican porque tienen invaginado el rostellum y las ventosas; sin embargo, cuando salen de los quistes liberan sus ventosas y la corona de ganchos, convirtiéndose en protoescólex infectantes (contenidos en quistes activos), tanto para la cavidad u órgano del hospedero intermediario (recurrencia o quistes hijos) como para el intestino del hospedero definitivo ${ }^{4}$. Algunos quistes no pueden producir protoescólices (el parásito muere) y se definen como quistes infértiles ${ }^{4}$. Las capas del parásito se rodean por otra capa originaria del hospedero intermediario: la capa adventicia ${ }^{4}$.

Las capas germinal y laminada forman una barrera que impide el paso de las células y de las proteínas menores que el tamaño de la IgG del hospedero intermediario ${ }^{4,6}$. Este mecanismo innato de defensa se debe a capas de mucopolisacáridos y queratina ${ }^{4}$. La capa laminada inhibe la proliferación de macrófagos (las mucinas de esta estructura están altamente glucosiladas y se unen a los receptores de las células de Kupffer o bien de otros macrófagos, y generan poca reacción inmunitaria celular) e induce la producción de arginasa, que inhibe la actividad del óxido nítrico (NO) y, por lo tanto, las células inmunitarias productoras de NO son incapaces de penetrar la barrera impuesta por esta capa ${ }^{5}$. Posteriormente, durante la maduración de la oncosfera y luego el quiste hidatídico evaden el sistema inmunitario activando la respuesta inmunitaria Th2 (la proteína del parásito $\mathrm{EgAgB}$ modula señales de inmunidad innata que sesgan hacia una respuesta inmunitaria Th2 ${ }^{6}$. Aunque en un principio también activan Th1 ${ }^{6}$, el paso crucial en esta respuesta Th2 es la expresión de citocinas supresoras (interleucina 10, factor de crecimiento transformante beta) y la expansión sistémica de FoxP3 de células $T$ reguladoras con la producción de grandes cantidades de interleucina 5 por los linfocitos $^{6}$. En los quistes activos predomina la respuesta Th2, mientras que en los quistes inactivos predomina la Th1 ${ }^{4}$. Otro mecanismo de evasión es la utilización de protoescólices o protoescólex muertos como cebo para el sistema inmunitario ${ }^{6}$.

La capa adventicia está compuesta por fibras de colágeno, fibroblastos, células epitelioides, células multinucleadas, eosinófilos y linfocitos (en ocasiones simula una reacción granulomatosa como la que genera un cuerpo extraño) ${ }^{7}$. La inmunidad celular 
elimina al parásito; se ha observado que en los pacientes infectados que logran una respuesta inmunitaria Th1 los quistes están inactivos o desaparecen ${ }^{6,7}$. Cuando los parásitos mueren (capa germinal infértil) se desorganiza la capa laminada de la germinal y se infiltran por las células inmunitarias, principalmente por macrófagos; luego los quistes colapsan, se calcifican y desaparecen de manera gradual (quistes inactivos) $)^{4,6}$.

Si se rompe el quiste dentro del hospedero intermedio se libera una gran cantidad de antígenos que producen una reacción anafiláctica. Posteriormente, los protoescólices liberados se pueden reimplantar y generar nuevos quistes, llamados quistes hijos (que se comportan fisiopatológicamente igual que el quiste hidatídico inicial) ${ }^{7}$.

En la naturaleza, al ingerir los hospederos definitivos vísceras o tejidos contaminados con quistes hidatídicos, los protoescólex se liberan en el estómago y el intestino delgado y se transforman en protoescólex (evaginan su corona de ganchos y ventosas), y entonces se fijan por medio de sus ganchos y ventosas al intestino delgado y se transforman en gusanos adultos en 32 a 80 días, reiniciando así nuevamente el ciclo?.

\section{Epidemiología}

Se trata de una zoonosis que el humano adquiere por transmisión fecal-oral. El ser humano es afectado por E. granulosus sensu stricto, E. canadensis, E. ortleppi, E. multilocularis, E. oligarthra y E. vogeli ${ }^{5}$. Los factores de riesgo para adquirirla son la dedicación a la agricultura, habitar 0 ir a zonas rurales, tener contacto con perros sin cuidados veterinarios (los perros son la principal fuente de infección para los seres humanos) o alimentados con vísceras contaminadas (en el entorno rural el ciclo biológico se da entre ovejas y perros pastores), asistencia a cacerías, consumo de alimentos al aire libre cerca de excrementos de perro (perros que deambulan libremente y tienen acceso a los despojos) o de otro hospedero definitivo, consumo de agua no hervida o procesada, y consumo de frutas sin lavar y desinfectar ${ }^{8}$. También se mencionan ciertas profesiones como factor de riesgo: matarifes, curtidores, ganaderos, pastores, carniceros y veterinarios $^{9}$. En nuestro caso, la paciente no tenía ningún factor de riesgo importante en la primera ocasión, y en la recurrencia su único antecedente importante era la cirugía 19 años antes por un quiste hidatídico.
Esta parasitosis tiene prevalencia mundial, pero las zonas endémicas difieren según el país y la región y están influenciadas por diferentes factores bióticos y abióticos. En general se encuentra en áreas rurales de cría de ganado, como el Mediterráneo, Europa del Este, África del Norte y del Este, América del Sur (Argentina, Brasil, Chile, Perú y Uruguay), Asia Central, China y Australia ${ }^{5}$. Esta enfermedad genera pérdidas económicas anuales en el comercio de carnes y pieles ${ }^{10}$. En México no se dispone de suficientes datos sobre su distribución.

\section{Cuadro clínico}

La mayoría de los pacientes cursan asintomáticos ${ }^{11}$. Si se presentan molestias, se deben al efecto compresivo del quiste sobre los tejidos adyacentes; por lo tanto, dependen del sitio anatómico donde se localizan, de su tamaño y de su número ${ }^{12}$. Existe una gran variedad de síntomas, pero no hay uno patognomóni$\mathrm{co}^{11}$. Los síntomas pueden manifestarse años después de la infección (10-15 años) debido al lento crecimiento de los quistes, en promedio $7 \mathrm{~mm}$ por $a \tilde{0} 0^{5}$. No obstante, se ha informado el crecimiento de 1-5 cm por año, que depende de la compresibilidad de las estructuras circundantes: el quiste crece más rápido en los pulmones y más lento en el hígado, el bazo y los riñones ${ }^{13}$. En caso de inmunosupresión (pacientes con virus de la inmunodeficiencia humana, receptores de trasplantes, con padecimiento oncológico o uso prolongado de inmunosupresores) o con un antígeno leucocitario humano HLA-DR3 DQ2, los quistes tienen un crecimiento más rápido y producen una enfermedad más grave y una respuesta inmunitaria de tipo Th2 más pronunciada².

La equinococosis afecta principalmente al hígado (70-75\%) y al pulmón (15-20\%), pero también puede localizarse en otros órganos, como el cerebro, el corazón, los huesos, los músculos, los riñones, el páncreas y la glándula tiroides ${ }^{11,12}$.

El quiste hidatídico hepático suele localizarse en el lóbulo derecho ( $80 \%$ de los casos) y se acompaña de dolor abdominal superior, saciedad temprana, pérdida de peso e hiperbilirrubinemia obstructiva, incluidos cuadros de colecistitis o colangitis ${ }^{13}$. En ocasiones, los quistes hidatídicos pueden llevar a una infección bacteriana secundaria y formar un absceso; esta infección se debe a la rotura de la capa laminada, que predispone a la colonización y la sobreinfección bacteriana $^{13}$. 
Los quistes peritoneales producen dolor abdominal, sensación de pesadez, aumento del volumen abdominal y saciedad temprana, como en nuestro caso clínico. Los quistes localizados en la cavidad abdominal se pueden clasificar, según Kjossev y Teodosiev ${ }^{14}$, en tres etapas según la profundidad de la invasión en la pared abdominal: estadio 1, lesiones hidatídicas que sobresalen hacia la capa muscular; estadio 2, quistes que pasan más allá de la capa muscular para invadir la capa subcutánea; y estadio 3 , quistes que pasan más allá del tejido subcutáneo para fistulizar la piel (lo que se denomina rotura externa o fistulización cutánea $)^{14}$. Nuestra paciente se clasificaría en el estadio 1.

La rotura traumática (lesión contundente, perforante, cirugía por otro motivo) o espontánea puede provocar fiebre, urticaria, eosinofilia y, en situaciones críticas, choque anafiláctico ${ }^{15}$. Los pacientes con rotura intraperitoneal presentan síntomas como dolor abdominal intenso, hipotensión, taquicardia y reacción alérgica. Los factores de riesgo para la rotura son la edad joven (mayor exposición a accidentes de tráfico que las personas mayores), el diámetro del quiste $>$ $10 \mathrm{~cm}$, la presión intraquística $>50 \mathrm{cmH}_{2} \mathrm{O}$ y la localización superficial de la lesión ${ }^{15}$. Se menciona que la rotura del quiste hidatídico hepático puede ocurrir en aproximadamente el $35 \%$ de los casos $^{15}$. Se clasifica, según Lewall y McCorkellit ${ }^{16}$ en tres tipos: 1) rotura comunicante, que es el tipo más común (15\%) y se define como el paso de material hidatídico desde el quiste al tracto biliar u otros órganos adyacentes; 2) rotura contenida (12\%), cuando las capas laminar y germinativa se rompen de la adventicia y el borde externo permanece intacto (en la TC, signo de la membrana flotante o de la serpiente); y 3) rotura directa $(6 \%)$, que genera la implantación de protoescólices en varios órganos abdominales (enfermedad recurrente o quistes hijas) y se puede acompañar de choque anafiláctico o abdomen agudo debido a una peritonitis inducida químicamente ${ }^{15}$. La tasa de incidencia de choque anafiláctico que puede ser mortal es de aproximadamente un $1.4 \%$, y las reacciones anafilácticas durante la cirugía en pacientes que no experimentan rotura del quiste pueden ocurrir en un $0.2-3.3 \%$ de los casos $^{15}$. Nuestra paciente, hace 19 años, presentó rotura directa.

La exploración física debe enfocarse hacia los síntomas del paciente. Se pueden encontrar hepatomegalia, esplenomegalia, tumor o distensión abdominal. Si el tumor es palpable, se puede describir que tiene un borde regular, es blando y móvil o parcialmente móvil. Para que un quiste hidatídico sea palpable en el abdomen, sus dimensiones deben ser considerables. Por ejemplo, en nuestro caso se palpaban dos tumores en ambos hipocondrios, los dos de bordes regulares y consistencia firme que hacían sospechar que se trataba de tumores quísticos. La palpación debe ser cuidadosa, evitando una manipulación traumática que podría precipitar la rotura del quiste.

\section{Diagnóstico}

El diagnostico se basa en los antecedentes personales (como en nuestro caso), los síntomas, la exploración física, los estudios de imagenología y los exámenes de laboratorio.

\section{ESTUDIOS DE IMAGENOLOGÍA}

Los estudios de imagen que se pueden solicitar como parte del diagnóstico son el ultrasonido (USG), la TC contrastada y la resonancia magnética (RM). La radiografía simple no es el mejor estudio para esta enfermedad. El ultrasonido está ampliamente disponible, es económico y no emite radiación; realizado por expertos, es la modalidad de elección para la detección y para el seguimiento del tratamiento ${ }^{17}$. El ultrasonido tiene una sensibilidad del $90-95 \%$ y una especificidad del $93-100 \%$, aunque depende de en qué sitio y en qué etapa del quiste se realice el diagnóstico ${ }^{17}$. Los hallazgos consisten en quistes que tienen «arena hidatídica», vesículas dentro de los quistes, quistes hijos o membranas flotantes por rotura contenida. Sin embargo, presenta limitaciones en pacientes obesos, en presencia de gases intestinales excesivos y en caso de deformación de la pared abdominal. La TC tiene unas altas sensibilidad (95-100\%) y especificidad para la detección de equinococosis ${ }^{18}$. A diferencia del ultrasonido, no es dependiente del operador y se pueden valorar la pared del quiste y si existen calcificaciones o estructuras intraquísticas. Además, proporciona al cirujano información para realizar un plan quirúrgico valorando la extensión anatómica ${ }^{17}$. La RM mejora el diagnóstico al permitir diferenciar los quistes hidatídicos del hígado de otros quistes hepáticos simples utilizando una secuencia ponderada por difusión ${ }^{17}$. En caso de complicaciones de la equinococosis, como la rotura y la sobreinfección, la TC y la RM son las técnicas de elección ${ }^{17}$. La RM podría considerarse en las mujeres embarazadas y en los niños 
en quienes se sospecha esta patología y el ultrasonido no ha sido concluyente.

Los hallazgos en los estudios imagenológicos son muy variados, desde lesiones quísticas gigantes hasta tumores pequeños de apariencia sólida, que pueden ser únicos o múltiples, uniloculares o multiloculares, septados o calcificados. Estos hallazgos dependen del sitio de localización (órgano afectado) y del estadio de evolución de la enfermedad (quistes fértiles, infértiles o complicados). Los quistes, por imagen, se clasifican en cuatro tipos como se muestra en la tabla $1^{17}$.

Otra clasificación imagenológica (por ultrasonido) es la del consenso WHO-IWGE (World Health Organization Informal Working Group on Echinococcosis), realizada en 2003 para guiar el tratamiento de la equinococosis. Esta incluye tres grupos: quiste activo CE1 (cystic echinococcosis 1) y CE2, quiste transicional CE3a y CE3b, y quiste inactivo CE4 y $\mathrm{CE} 5^{19}$ (Tabla 2).

Con los estudios de imagen, la clínica y los antecedentes es posible establecer el diagnóstico, pero en caso de duda se pueden considerar estudios de laboratorio.

\section{ESTUDIOS DE LABORATORIO}

Respecto a los estudios de laboratorio, la detección de anticuerpos IgG en suero del paciente contra los antígenos del parásito por ensayo de inmunoabsorción ligado a enzimas (ELISA) es el método de referencia ${ }^{20,21}$. Otras opciones para detectar este anticuerpo y otros son la hemaglutinación indirecta, o aglutinación de látex, con antígenos del líquido del quiste hidatídico, cuya sensibilidad varía entre el $85 \%$ y el $98 \%$ para los quistes hepáticos, entre el $50 \%$ y el $60 \%$ para los pulmonares y entre el $90 \%$ y el $100 \%$ para los de múltiples órganos ${ }^{22}$. Sin embargo, debe tenerse en cuenta que estos anticuerpos se dirigen contra distintos antígenos del parásito (son heterogéneos, los antígenos se expresan de manera diferente en cada etapa del quiste), no existe un antígeno específico (los más descritos son el antígeno $\mathrm{B}$ y el antígeno 5, aunque existen muchos más) y varían dependiendo del tamaño del quiste, la localización y el tiempo de evolución de la enfermedad. La serología con frecuencia es negativa en quistes calcificados, muertos o viejos ${ }^{2}$. Tampoco la serología podría ser adecuada en la primera línea de diagnóstico en poblaciones donde la enfermedad es endémica, porque muchos individuos sin enfermedad serían positivos y viceversa, individuos con la enfermedad podrían ser negativos debido a un estado de inmunosupresión ( $p$. ej., por desnutrición) ${ }^{23-25}$. Otro aspecto limitante en la serología es que los anticuerpos dirigidos contra estos parásitos pueden hacer reacción cruzada con los producidos contra el género Taenia ${ }^{22}$.

El examen de coproparásitos en los pacientes no está indicado puesto que no hay huevos (el humano no es el hospedador definitivo) ni parásitos en las heces, como se describió previamente en el ciclo biológico.

Se pueden identificar los antígenos del parásito en el líquido del quiste hidatídico. En este examen se encuentran principalmente el antígeno $\mathrm{B}$ y el antígeno 5 . Estos se pueden detectar por medio de electroforesis, aglutinación o inmunofluorescencia directa, o inmunotinción específica 2,21,23.

Otro estudio es el examen directo en fresco en el microscopio óptico de un frotis del líquido, en el cual se pueden identificar los protoescólices del parásito (Fig. 4). El examen histopatológico solo sirve para confirmar finalmente el diagnóstico (Fig. 5).

Se han realizado estudios de la proteómica del parásito en el líquido del quiste, pero aún está en investigación utilizarla como marcador de respuesta al tratamiento médico ${ }^{26}$. Se puede optar por detectar el ADN del parásito en las muestras del líquido del quiste mediante reacción en cadena de la polimerasa (PCR); sin embargo, solo está indicada en biopsias o en muestras del líquido del quiste en pacientes con imágenes inusuales, con serología negativa o tipificados como pacientes inmunosuprimidos ${ }^{27,28}$. Últimamente se está investigando como método diagnóstico la detección de ADN libre de células en el plasma de pacientes con equinococosis ${ }^{29,30}$.

Existen pruebas rápidas que pueden ser útiles en entornos con escasos recursos para complementar el diagnóstico ecográfico de la hidatidosis en casos inciertos. En la literatura se menciona que la prueba VIRAPID $®$ parece funcionar mejor que otros kits examinados, pero todas las pruebas son poco sensibles en presencia de quistes inactivos, lo que puede plantear problemas para un diagnóstico preciso ${ }^{31}$.

Otra estudio inmunitario es la prueba intradérmica de Casoni, que se puede utilizar para confirmar el diagnóstico con los resultados de imagenología, pero tiene poca sensibilidad (63.8\%), escasa especificidad (47\%), mala estandarización, problemas éticos con respecto a los reactivos de origen animal inyectados en humanos, y poca disponibilidad de antígenos 
Tabla 1. Clasificación de los quistes hidatídicos por estudios de imagen y fisiopatología (datos obtenidos de ref. 16)

\begin{tabular}{|c|c|c|c|c|}
\hline Tipo & $\begin{array}{l}\text { Principal } \\
\text { característica }\end{array}$ & Descripción & Tomografía computarizada & Resonancia magnética \\
\hline । & $\begin{array}{l}\text { Quiste simple } \\
\text { sin arquitectura } \\
\text { interna }\end{array}$ & $\begin{array}{l}\text { Etapa inicial de desarrollo } \\
\text { Lesión quística unilocular bien definida, } \\
\text { sin arquitectura interna, con o sin arena } \\
\text { hidatídica o septos internos }\end{array}$ & Contraste: realza la pared y los tabiques & $\begin{array}{l}\text { Borde hipointenso en las } \\
\text { imágenes T2 } \\
\text { Diferenciación de hidatídico } \\
\text { tipo I y quiste simple }=\text { el } \\
\text { coeficiente de difusión es } \\
\text { menor en los hidatídicos } \\
(2,5 \times 103 \pm 0,9) \text { que en los } \\
\text { simples }(3,5 \times 103 \pm 0,5) .\end{array}$ \\
\hline ॥ & $\begin{array}{l}\text { Quiste con } \\
\text { quiste (s) hijo } \\
\text { (s) o matriz }\end{array}$ & $\begin{array}{l}\text { Los quistes multiloculares = colección } \\
\text { líquida con múltiples tabiques internos } \\
\text { (quistes hijos), que se disponen en la } \\
\text { periferia }\end{array}$ & $\begin{array}{l}\text { Los quistes hijos tienen una densidad menor } \\
\text { que la del quiste madre (patrón en panal) } \\
\text { Tres subtipos: IIA (apariencia de radios de } \\
\text { rueda), IIB (apariencia de roseta) y IIC (quiste } \\
\text { madre muerto [calcificaciones] y quiste hijo } \\
\text { activo) }\end{array}$ & $\begin{array}{l}\text { Los quistes hijos son } \\
\text { hipointensos o isointensos } \\
\text { en } \mathrm{T} 1 \text { y T2, con periquiste } \\
\text { hipointenso en T2 }\end{array}$ \\
\hline III & $\begin{array}{l}\text { Quiste } \\
\text { calcificado }\end{array}$ & $\begin{array}{l}\text { El parásito está muerto, hay respuesta } \\
\text { inmunitaria Th1 } \\
\text { Presenta calcificación de la pared, la } \\
\text { matriz interna y las membranas } \\
\text { Calcificación densa completa = quiste } \\
\text { inactivo }\end{array}$ & $\begin{array}{l}\text { Método de imagen preferido para evaluar los } \\
\text { quistes hidatídicos calcificados } \\
\text { Aparecen como lesiones hiperdensas bien } \\
\text { definidas }\end{array}$ & $\begin{array}{l}\text { Se observan zonas } \\
\text { hipointensas }\end{array}$ \\
\hline IV & $\begin{array}{l}\text { Quiste } \\
\text { hidatídico } \\
\text { complicado }\end{array}$ & $\begin{array}{l}\text { Rotura contenida: signo de la serpiente o } \\
\text { membranas flotantes («signo del nenúfar») } \\
\text { Rotura directa: líquido en cavidad } \\
\text { abdominal, derrame pleural, pared } \\
\text { abdominal } \\
\text { Niveles internos de gas, líquido-líquido o } \\
\text { aire-líquido o grasa = signos indirectos } \\
\text { de infección o comunicación con vísceras } \\
\text { huecas o árbol biliar }\end{array}$ & $\begin{array}{l}\text { Rotura contenida: signo de la serpiente o } \\
\text { )membranas flotantes } \\
\text { Rotura comunicante: fistuliza el quiste hacia la } \\
\text { vía biliar, los bronquios u otras localizaciones, } \\
\text { se observa en la imagen } \\
\text { Niveles internos de gas, líquido-líquido o } \\
\text { aire-líquido o grasa = signos indirectos de } \\
\text { sinfección o comunicación con vísceras huecas } \\
\text { o árbol biliar }\end{array}$ & \\
\hline
\end{tabular}

recombinantes, por lo que se ha limitado considerablemente su uso para el diagnóstico de hidatidosis. No obstante, cuando se combina con otras, como la prueba de hemaglutinación indirecta, podría establecerse el diagnóstico hasta en el $90.9 \%$ de los casos de equinococosis ${ }^{32}$.

En nuestro caso teníamos una alta sospecha del diagnóstico por el antecedente de la paciente, los síntomas, la exploración física y los hallazgos de la TC. No disponemos en nuestro hospital de pruebas inmunológicas ni pruebas rápidas, por lo que no se realizaron. Tampoco se hizo punción percutánea con fines diagnósticos y terapéuticos (PAIR, Percutaneous Puncture, Aspiration, Injection, Reaspiration) porque la paciente tenía criterios de cirugía. El diagnóstico se confirmó en el posquirúrgico con el análisis en fresco del líquido del quiste en el microscopio óptico (Fig. 4), y finalmente con el reporte histopatológico (Fig. 5).

En los pacientes inmunosuprimidos es difícil el diagnóstico porque usualmente no producen tantos anticuerpos como para detectarlos en el plasma. En ellos, para establecer el diagnóstico es razonable la aspiración del quiste y el análisis del líquido.

\section{Tratamiento}

El tratamiento de los quistes hidatídicos es multidisciplinario e incluye médicos de atención primaria, parasitólogos, cirujanos, endoscopistas, infectólogos y radiólogos intervencionistas, entre otros. El tratamiento es complejo porque depende de la localización, el tamaño, el número, los síntomas, el tratamiento previo, el estado del quiste (activo, en transición o inactivo), la recurrencia, las complicaciones, la comorbilidad, la decisión del paciente, los recursos disponibles y la experiencia de cada centro de atención.

En general, el tratamiento puede clasificarse en cuatro tipos: médico (benzimidazol), mínimamente invasivo (PAIR), quirúrgico y, en ocasiones, un enfoque de «observar y esperar»", Los tratamientos no son excluyentes y pueden combinarse. 
Tabla 2. Clasificacion de los quistes según la WHO-IWGE (información resumida de ref. 18)

\begin{tabular}{|c|c|}
\hline Clasificación & Características \\
\hline CE1 & $\begin{array}{l}\text { Quiste simple unilocular, contenido anecoico, forma } \\
\text { circular u oval } \\
\text { Signo de copo de nieve }\end{array}$ \\
\hline CE2 & $\begin{array}{l}\text { Quiste multivesicular o multitabicado por quistes hijos } \\
\text { Signos de la rueda, de la roseta o del panal de abeja }\end{array}$ \\
\hline CEЗа & $\begin{array}{l}\text { Rotura contenida: quiste anecoico con presencia } \\
\text { en su interior de una o más líneas ondulantes } \\
\text { hiperecogenicas que representan el desprendimiento } \\
\text { de la capa germinal/laminada de la adventicia } \\
\text { Signo del nenúfar o de la serpiente }\end{array}$ \\
\hline CE3b & $\begin{array}{l}\text { Complejo de masas, quistes uniloculares que } \\
\text { contienen quistes hijos (anecoicos) con presencia } \\
\text { de áreas ecoicas (por disrupción de membranas o } \\
\text { degeneración de quistes hijos) }\end{array}$ \\
\hline CE4 & $\begin{array}{l}\text { Quiste con contenido heterogéneo hipoecoico o } \\
\text { dishomogéneo degenerativo, no tiene quistes hijos } \\
\text { (hipoecogénicos) } \\
\text { Signo de la bola de lana }\end{array}$ \\
\hline CE5 & $\begin{array}{l}\text { Quiste con pared gruesa calcificada, pared del } \\
\text { quiste que proyecta sombra en forma de cono, y el } \\
\text { grado de calcificación varía de parcial a completo }\end{array}$ \\
\hline
\end{tabular}

El tratamiento con un benzimidazol puede ser con albendazol o con mebendazol. No hay otros medicamentos para este parásito, aunque se ha descrito el uso exitoso del antifúngico anfotericina $B$ en algunos casos de fístula cistocutánea en pacientes con afectación hepática, intolerancia al benzimidazol o resistentes al tratamiento ${ }^{14}$. Para desarrollar otro compuesto eficaz en esta parasitosis es necesario que sea escolicida y actúe a nivel sistémico, que sea soluble, que tenga una adecuada biodisponibilidad intraquiste, que tenga un régimen de fácil administración, que resulte económico y que no presente efectos secundarios. La monensina, el praziquantel, el imatinib y el 2-metoxiestradiol pueden cumplir la mayoría de estos requisitos, pero se necesitan más ensayos in vivo para demostrar su eficacia y seguridad ${ }^{33}$. Debido a su mayor biodisponibilidad y administración más fácil, el albendazol se prefiere como tratamiento antiinfeccioso de elección a una dosis promedio de $15 \mathrm{mg} / \mathrm{kg}$ al día. El mebendazol es un fármaco alternativo para aquellos pacientes que han experimentado efectos adversos hepáticos graves con el albendazol. Ambos están indicados cuando no es posible el tratamiento quirúrgico (por contraindicación o por rechazo de los pacientes), si falla la PAIR, en caso de múltiples quistes y en combinación con PAIR o cirugía. Los esquemas de tratamiento son muy variables, pero en general se recomienda 1 semana antes del procedimiento (cirugía o PAIR) y continuar hasta por 2 meses posteriores ${ }^{2,34,35}$. Otros recomiendan el tratamiento hasta por 11 a 12 meses debido a que no se logran concentraciones intraquísticas suficientes ${ }^{12,17}$. Durante el tratamiento, por la toxicidad del fármaco, se deben realizar pruebas de función hepática y biometría hemática. En los pacientes inmunodeprimidos se debe considerar la reducción del tratamiento inmunosupresor si es posible ${ }^{27}$.

La técnica PAIR, que consiste en la punción, aspiración, inyección (protoscolecida) y reaspiración de los quistes, se ha convertido en una opción terapéutica intervencionista para quistes CE1 y CE3a de tamaño medio $(>5 \mathrm{~cm})$ y en pacientes que rechazan la cirugía $^{22}$. Existe una modificación de la PAIR, llamada «técnica de cateterismo modificada», que es un procedimiento apropiado para quistes de hasta $10 \mathrm{~cm}$ de diámetro; se realiza la aspiración y se deja un catéter dentro del quiste para su drenaje ${ }^{2}$. También se ha probado con éxito en quistes CE2 y CE3b no complicados, pero debe recordarse que son más quistes, por lo que el riesgo de hemorragia, rotura y lesión de víscera podría aumentar². Un metaanálisis comparó la técnica PAIR frente al drenaje laparoscópico y concluyó que el procedimiento PAIR es mejor que la laparoscopia porque tiene una mayor tasa de curación y menores tasas de complicaciones y de mortalidad; sin embargo, la laparoscopia presenta una tasa de recurrencia más baja ${ }^{34}$. Por ello, para algunos el tratamiento es esencialmente quirúrgico ${ }^{1,2}$.

Se ha descrito un algoritmo de tratamiento del quiste hidatídico en el hígado en función del estadio OMS-IWGE, el tamaño del quiste y si es resecable ${ }^{18}$. En general, los quistes en estadio C1 y C3a que miden $<5 \mathrm{~cm}$ pueden tratarse con albendazol solo. Los quistes que miden $>5 \mathrm{~cm}$ pueden tratarse con PAIR sola o en combinación con albendazol ${ }^{22}$. El tratamiento de los quistes en estadio CE-2 y CE-3b, que tienen muchos compartimentos, requiere una técnica de cateterismo modificada o cirugía (con tratamiento farmacológico complementario). Los estadios CE-4 y CE-5 son quistes inactivos que pueden manejarse con observación, pero si presentan síntomas asociados, la cirugía es la elección ${ }^{22}$.

El tratamiento curativo se logra con la eliminación completa del quiste. En general, las indicaciones de cirugía son quiste único de diámetro $>10 \mathrm{~cm}$, quiste superficial con riesgo de rotura, quiste roto, quistes 
que comprimen estructuras vitales, quistes con infección secundaria o hemorragia, quistes complejos con quistes hijos (C2, C3b) y quistes asociados a abdomen agudo ${ }^{15.16,18,22}$. No está indicada en los pacientes con contraindicaciones generales para la cirugía, quistes muy pequeños, quistes de difícil acceso o quistes asintomáticos clasificados como inactivos ${ }^{22}$.

El abordaje quirúrgico depende del sitio, del tamaño del quiste, de las complicaciones perioperatorias y de la preferencia del cirujano. Sin embargo, debe seguir el principio general de todos los quistes hidatídicos: resección completa evitando la perforación y el derrame de su líquido, por dos problemas, que son la anafilaxia y la recurrencia de la enfermedad ${ }^{15,35}$. La técnica de elección es la cistectomía total (también conocida como cistectomía periadventicial 0 , incorrectamente "pericistectomía»), que evita la apertura del quiste ${ }^{35}$. Respecto al margen quirúrgico, se ha descrito que se necesita de $1 \mathrm{~mm}$ a $1 \mathrm{~cm}$ libre de lesión para considerarlo adecuado ${ }^{14,36}$. Cuando el quiste está adyacente a estructuras vitales y vasos principales, se recomienda la cistectomía subtotal (se deja hasta la capa adventicia). Si ambas técnicas no son factibles se puede realizar una hidatidectomía (también llamada endocistectomía o cistectomía parcial, en la que solo se eliminan parcialmente las tres capas del quiste) después de la apertura del quiste ${ }^{1,2}$. En otros casos se requerirá la exéresis de tejido sano periquístico (p. ej., una hepatectomía), y la resección incluso puede ser junto con estructuras vecinas (resección en bloque: músculo, aponeurosis, tejido celular subcutáneo, piel), aunque estos procedimientos incrementan la morbilidad (insuficiencia hepática, asplenia, paciente monorreno). En nuestro caso, al final se realizó una resección en bloque incluyendo el peritoneo parietal anterior, las fascias anterior y posterior, y parte del músculo recto del abdomen (morbilidad: hernia inicisional).

Respecto al abordaje abierto, laparoscópico o robótico, se ha demostrado que la mínima invasión (laparoscópico o robótico) es mejor debido a que se reducen la estancia intrahospitalaria, el dolor posquirúrgico y la infección en el sitio quirúrgico, permite una rápida incorporación a la actividad diaria de los pacientes y proporciona mejor calidad de vida ${ }^{35,37}$. Sin embargo, se prefiere la cirugía abierta o la conversión a esta en las siguientes situaciones: contraindicación para cirugía mínimamente invasiva (p. ej., paciente con choque), inexperiencia del cirujano en esta técni$\mathrm{ca}$, complicaciones intraoperatorias que el cirujano no puede resolver por técnica de mínima invasión (hemorragia), ausencia de recursos tecnológicos y enfermedad recurrente que incluye varios elementos, por ejemplo, de la pared abdominal. En la cirugía abierta, el tipo de incisión de la pared abdominal debe ser individualizado, pero siempre bajo el principio de resección sin apertura del quiste.

Para los quistes de localización hepática exclusiva se ha descrito una nomenclatura quirúrgica universal que tiene el acrónimo AORC: Approach (enfoque: Iaparotomía, laparoscopia o robótica), Opening (apertura: quiste abierto o cerrado), Resection (resección: cistectomía, hepatectomía o trasplante hepático) y Completeness (extracción: completa, subtotal o parcial).

Se han probado diversas sustancias como protoscolecidas (matan los protoescólices o protoescólex) que se pueden usar intraoperatoriamente o bien durante el procedimiento PAIR, de las cuales la OMS-IWGE recomienda la solución salina hipertónica al 20\% como protoscolecida preferido en cirugía (lavar la cavidad peritoneal al menos dos veces en 10 minutos, durante 10-15 minutos cada vez) ${ }^{15,19}$. En el caso de la PAIR se recomienda solución salina hipertónica al $20 \%$ o alcohol al $95 \%$. Otros productos que podrían administrarse durante la PAIR siguen en investigación, y otros son parte del protocolo de atención en centros de gran volumen y se producen regionalmente ${ }^{2,34}$.

En nuestra paciente se trataba de una recurrencia de quistes hidatídicos con localización hepática y extrahepática hacia el peritoneo parietal. La cirugía fue programada y previamente a esta se interconsultó con medicina interna para valorar el riesgo quirúrgico, con infectología para recomendación del tratamiento y con alergología para recomendaciones periperatorias. Se optó por medicación preoperatoria (1 semana previa), perioperatoria y posquirúrgica por 12 meses debido al gran número de quistes y el derrame de líquido. El tratamiento se realizó con albendazol. También se optó por medicación perioperatoria a base de antihistamínico y esteroide (recomendado por alergología), previo a la cirugía y hasta las 48 horas posquirúrgicas. No se presentó reacción anafiláctica. Se usaron antibiótico profiláctico y analgésico. Los cuidados posquirúrgicos son los generales de toda cirugía y van enfocados a la incorporación a la vida diaria y a la detección de complicaciones posquirúrgicas. Nuestra paciente presentó atelectasia, pero fue egresada del hospital sin otras eventualidades.

Cuando se piense realizar cirugía paliativa, esta no se recomienda porque incrementa la morbilidad y la mortalidad; por ejemplo, en los quistes hidatídicos 
asociados a fístula biliar por afectación de la vía biliar principal la derivación biliodigestiva no se recomienda, y lo mejor en este caso es la colocación de stents endoscópicos o el drenaje biliar percutáneo².

En los quistes hidatídicos hepáticos con o sin cirrosis se ha descrito el trasplante hepático, con una supervivencia a 5 años cercana al $70 \%$ y una supervivencia libre de recurrencia del 58\%; sin embargo, el uso de inmunosupresores se podría asociar a un incremento del tamaño de los quistes y la persistencia de los parásitos ${ }^{38}$. También se ha estudiado extirpar el hígado del paciente, realizar la exéresis de los quistes hidatídicos fuera de la cavidad abdominal y por último volver a implantar el órgano como si fuera un trasplante (resección hepática ex vivo con autotrasplante) $)^{1,2}$. La ventaja es que no se usan inmunosupresores tras el reimplante hepático, pero se debe tener en cuenta el riesgo de desarrollar insuficiencia hepática aguda o crónica debido al poco tejido sano del remanente hepático implantado. Se ha descrito también el uso de un tipo de electrodo de ablación por radiofrecuencia que ofrece buenos resultados ${ }^{39}$.

Las complicaciones más comunes relacionadas con los quistes hidatídicos son sobreinfección, fístula cistobiliar (ictericia obstructiva, colangitis), reacciones alérgicas, rotura del sistema gastrointestinal (duodeno, intestino delgado, colon), síndrome de Budd-Chiari, hipertensión portal, obstrucción de la salida gástrica, glomerulonefritis membranosa, fístula broncobiliar, fístula broncopleural, rotura intrapericárdica, rotura intrapleural y rotura intraperitoneal ${ }^{2,13}$. La descripción, la fisiopatología, el diagnóstico, el tratamiento y el pronóstico se encuentran fuera del alcance de este texto.

\section{Pronóstico}

El pronóstico depende de múltiples factores, como la edad del paciente, la comorbilidad, la situación en que se hizo el diagnóstico (por hallazgos aislados o por la clínica), la localización del quiste, el tamaño del quiste, el abordaje quirúrgico, las complicaciones perioperatorias (sangrado, reintervención, fístula, infección, choque anafiláctico, etc.), el apego al tratamiento médico del paciente y la recurrencia. En general, las tasas de morbilidad y mortalidad después de una rotura intraperitoneal son del $10-35.3 \%$ y del $0-23.5 \%$, respectivamente ${ }^{16}$. La tasa de recurrencia después de la rotura de un quiste hidatídico intraperitoneal se informa entre el $0 \%$ y el $28.6 \%{ }^{16}$. Por el momento, nuestra paciente tiene buen pronóstico.

\section{Seguimiento}

Posterior al tratamiento se acepta un seguimiento estrecho durante al menos 5 años debido a las tasas de recaída en ese tiempo². Posterior a la PAIR, la cirugía y el albendazol se recomienda el seguimiento en las semanas 1, 4 y 12 durante los primeros 3 meses después del diagnóstico y del inicio del albendazol, con el fin de evaluar sus posibles efectos adversos, para lo cual son necesarias una biometría hemática y pruebas de función hepática, ya que la toxicidad hepática y la leucopenia son los efectos adversos más graves de este fármaco ${ }^{33}$. La tomografía por emisión de positrones con 5-fluorodesoxiglucosa (FDG-PET) se considera actualmente el método de referencia para la evaluación de la actividad metabólica de los quistes hidatídicos y para las decisiones sobre la interrupción del tratamiento antiinfeccioso (se recomienda realizarla al final del segundo año de tratamiento); las imágenes se obtienen 3 horas después de la inyección de FDG $^{2}$. El ultrasonido y la TC también son ideales para valorar la recurrencia, la localización, el tamaño, el número y la viabilidad de los nuevos quistes hijos (en nuestro caso se realizó TC), si no se dispone de FDG-PET.

La detección y la cuantificación de los anticuerpos en el suero del paciente no se considera lo mejor para valorar la cura de la enfermedad, pero pueden utilizarse como complemento junto con un estudio de imagen.

Durante el seguimiento de 5 años se recomienda la consulta cada 3 meses durante el primer año y cada 6 meses hasta el final del segundo año. El seguimiento debe incluir ecografía, hemograma, transaminasas y serología ${ }^{2}$. En caso de alteración en los análisis sanguíneos se debe medir el metabolito del albendazol en suero y ajustar la dosis, y se mide nuevamente a las 2-4 semanas después del cambio². El albendazol se retira si no hay recurrencia en el ultrasonido, la FDG-PET y la serología en al menos dos evaluaciones consecutivas, o en caso de toxicidad persistente a pesar del ajuste de dosis².

En nuestra paciente optamos por pruebas de función hepática en 3 meses debido al consumo del antiparasitario y TC de control en 6 meses debido a que no contamos con FDG-PET ni determinación de anticuerpos en nuestro centro de atención; esto podría considerarse como alternativa en aquellos centros de atención con recursos similares. 


\section{Prevención}

La prevención primaria es una cuestión no solo de la región o del país, sino de varias naciones. Va enfocada a mejorar los hábitos higiénicos, el consumo de agua potable o hervida, frutas y verduras lavados y desinfectados, y un programa de desparasitación frecuente en perros con praziquantel (al menos ocho veces al año) $)^{2}$. La vacunación de los perros es una parte importante de la prevención de esta parasito$\mathrm{sis}^{40}$. Se debe evitar alimentar a los perros con carne, vísceras u órganos de animales infectados con el parásito. Otras acciones incluyen mejorar la higiene en los mataderos, implementar campañas de educación y atención primaria de salud, la vacunación de ovinos (vacuna EG95) y el sacrificio de ovinos viejos ${ }^{8}$.

La prevención secundaria se enfoca en el tratamiento, como anteriormente se describió. El paciente debe comprometerse a cumplir el tiempo y la dosis del antiparasitario.

La prevención terciaria debe individualizarse dependiendo de las secuelas de la infección por el quiste hidatídico. En nuestra paciente, por el momento nos encontramos en la prevención secundaria (cumplir el esquema de tratamiento) y terciaria (dar seguimiento y posteriormente, en el futuro, reparar la hernia incisional si la presenta).

\section{Conclusiones}

La equinococosis es una enfermedad que debe tenerse en cuenta ante pacientes con una heterogeneidad de síntomas y que presentan una lesión quística en estudios de imagenología. Lo más importante en el quiste hidatídico es la detección y el tratamiento oportuno en las formas primarias, y más aún en la enfermedad recurrente, con el fin de prevenir las complicaciones asociadas a esta enfermedad (p. ej., sobreinfección y choque anafiláctico). El diagnóstico se establece con los antecedentes, los síntomas y los estudios de imagen, y se complementa con serología 0 análisis directo del líquido. El tratamiento siempre debe ser individualizado, tomando en cuenta la edad del paciente, la comorbilidad, la situación en que se hizo el diagnostico (por hallazgos aislados o por clínica), la localización del quiste, el tamaño, el número y la actividad del quiste, las complicaciones de la enfermedad, los síntomas, los deseos del paciente y los recursos terapéuticos disponibles. El tratamiento puede ser médico, con PAIR o con cirugía, o con una combinación de ellos. La cirugía siempre será la elección, complementada con un benzimidazol.

México se podría considerar una zona endémica por los múltiples factores de riesgo que nuestra la población y que comparte con otros países de América del Sur, además de que es un país de tránsito para inmigrantes de Latinoamérica hacia los Estados Unidos de América (muchos de ellos llevan sus mascotas). Es probable que el cirujano mexicano se enfrente a esta parasitosis, para lo cual les disponemos esta herramienta. En nuestros hospitales públicos quizá no tengamos pruebas sofisticadas, como PCR o detección de anticuerpos, por lo que proponemos la realización de la PAIR y el análisis directo en fresco del líquido del quiste con microscópica óptica, o bien, si no tenemos este apoyo, el tratamiento quirúrgico deberá considerarse de elección. Esperemos que en el futuro existan nuevos medicamentos para esta enfermedad y las vacunas estén al alcance de los hospederos definitivos e intermedios en nuestros países latinoamericanos.

\section{Agradecimientos}

Agradecemos a todo el equipo de trabajo de nuestro hospital.

\section{Responsabilidades éticas}

Protección de personas y animales. Los autores declaran que para esta investigación no se han realizado experimentos en seres humanos ni en animales.

Confidencialidad de los datos. Los autores declaran que han seguido los protocolos de su centro de trabajo sobre la publicación de datos de pacientes.

Derecho a la privacidad y consentimiento informado. Los autores han obtenido el consentimiento informado de los pacientes y/o sujetos referidos en el artículo. Este documento obra en poder del autor de correspondencia.

\section{Financiamiento}

Durante este trabajo no se recibió financiamiento por parte de alguna empresa.

\section{Conflicto de intereses}

Los autores declaran no tener conflictos de intereses. 


\section{Bibliografía}

1. Vuitton DA, McManus DP, Rogan MT, Romig T, Gottstein B, Naidich A et al.; World Association of Echinococcosis. International consensus on terminology to be used in the field of echinococcoses. Parasite. 2020;27:41.

2. Wen H, Vuitton L, Tuxun T, Li J, Vuitton DA, Zhang W, et al. Echinococcosis: advances in the $21^{\text {st }}$ Century. Clin Microbiol Rev. 2019;32:e00075-18

3. Gemmell MA. Safe handling of infected definitive hosts and eggs of Echinococcus spp. Bull WHO. 1968;39:122-5

4. Hidalgo C, Stoore C, Strull K, Franco C, Corrêa F, Jiménez M, et al. New insights of the local immune response against both fertile and infertile hydatid cysts. PloS One. 2019;14:e0211542.

5. Wen H, Vuitton L, Tuxun T, Li J, Vuitton DA, Zhang W, et al. Echinococcosis: advances in the $21^{\text {st }}$ Century. Clin Microbiol Rev. 2019;32:e00075-18.

6. Díaz A, Casaravilla C, Barrios AA, Ferreira AM. Parasite molecules and host responses in cystic echinococcosis. Parasite Immunol. 2016;38:193205.

7. Zhang $R Q$, Chen $X H$, Wen $H$. (2017). Improved experimental model of hepatic cystic hydatid disease resembling natural infection route with stable growing dynamics and immune reaction. World J Gastroenterol. 2017:23:7989-99.

8. Possenti A Manzano-Román R, Sánchez-Ovejero C, Boufana B, La Torre G, Siles-Lucas M, et al. Potential risk factors associated with human cystic echinococcosis: systematic review and meta-analysis. PLoS Negl Trop Dis. 2016;10:e0005114.

9. Farahmand M, Yadollahi M. Echinococcosis: an occupational disease. Int J Occup Environ Med. 2010;1:88-91.

10. Abdulhameed MF, Habib I, Al-Azizz SA, Robertson I. Cystic echinococcosis in marketed offal of sheep in Basrah, Iraq: Abattoir-based survey and a probabilistic model estimation of the direct economic losses due to hydatid cyst. Parasite Epidemiol Control. 2018;3:43-51.

11. Manzano-Román R, Sánchez-Ovejero $C$, Hernández-González A, CasuIli A, Siles-Lucas M. Serological diagnosis and follow-up of human cystic echinococcosis: a new hope for the future? BioMed Res Int. 2015;2015:428205.

12. Jiang $T$, Guo $Q$, Ran B, Zhang R, Aji T, Shao Y. Hydatid cyst of the thyroid gland with tracheal fistula: a case report and review of the literature. Exp Ther Med. 2019;18:573-9.

13. Greco S, Cannella R, Giambelluca D, Pecoraro G, Battaglia E, Midiri M, et al. Complications of hepatic echinococcosis: multimodality imaging approach. Insights Imaging. 2019;10:113.

14. Akbulut S. Parietal complication of the hydatid disease: comprehensive literature review. Medicine. 2018;97:e10671.

15. Akbulut S, Ozdemir F. Intraperitoneal rupture of the hydatid cyst: four case reports and literature review. World J Hepatol. 2019;11:318-29.

16. Lewall $D, M c C o r k e l l ~ S$. Rupture of echinococcal cysts: diagnosis, classification, and clinical implications. AJR Am J Roentgeno 1986;146:391-4

17. Mehta P, Prakash M, Khandelwal N. Radiological manifestations of hydatid disease and its complications. Trop Parasitol. 2016;6:103-12

18. Zhuoli Z, Yu Z, Liya X, Mingzhong L, Shengwei L. Case report: Laparoscopic excision of a primary giant splenic hydatid cyst: literature review. Am J Trop Med Hyg. 2019;101:821-7.

19. WHO Informal Working Group. International classification of ultrasound images in cystic echinococcosis for application in clinical and field epidemiological settings. Acta Trop. 2003:85:253-61.

20. Youssefi MR, Mirshafiei S, Moshfegh Z, Soleymani N, Rahimi MT. Cystic echinococcosis is an occupational disease? J Parasit Dis. 2016;40:586-90.
21. Manzano-Román R, Sánchez-Ovejero C, Hernández-González A, CasuIli A, Siles-Lucas M. Serological diagnosis and follow-up of human cystic echinococcosis: a new hope for the future? BioMed Res Int. 2015;2015:428205.

22. Wang S, Yang T, Zhang X, Xia J, Guo J, Wang X, et al. Construction of in vivo fluorescent imaging of echinococcus granulosus in a mouse model. Korean J Parasitol. 2016;54:291-9.

23. Cisak E, Sroka J, Wójcik-Fatla A, Zając V, Dutkiewicz J. Evaluation of reactivity to Echinococcus spp. among rural inhabitants in Poland. Acta Parasitol. 2015;60:525-9.

24. Bartholomot G, Vuitton DA, Harraga S, Shi DZ, Giraudoux P, Barnish G et al. Combined ultrasound and serologic screening for hepatic alveolar echinococcosis in central China. Am J Trop Med Hyg. 2002;66:23-9.

25. Chauchet A, Grenouillet F, Knapp J, Richou C, Delabrousse E, Dentan C, et al. Increased incidence and characteristics of alveolar echinococcosis in patients with immunosuppression-associated conditions. Clin Infect Dis. 2014;59:1095-104.

26. Valot B, Rognon B, Prenel A, Baraquin A, Knapp J, Anelli M, et al. Screening of antigenic vesicular fluid proteins of Echinococcus multilocularis as potential viability biomarkers to monitor drug response in alveolar echinococcosis patients. Proteomics Clin Appl. 2017;11:11-2.

27. Brunetti E, Kern $P$, Vuitton DA. Expert consensus for the diagnosis and treatment of cystic and alveolar echinococcosis in humans. Acta Trop. 2010;114:1-16

28. Georges S, Villard O, Filisetti D, Mathis A, Marcellin L, Hansmann Y, et al. Usefulness of PCR analysis for diagnosis of alveolar echinococcosis with unusual localizations: two case studies, J Clin Microbiol. 2004;42:5954-6.

29. Ji J, Li B, Li J, Danzeng W, Li J, Zhao Y, et al. Comprehensive characterization of plasma cell-free Echinococcus spp. DNA in echinococcosis patients using ultra-high-throughput sequencing. PLoS Negl Trop Dis. 2020;14:e0008148.

30. Wan Z, Peng X, Ma L, Tian Q, Wu S, Li J, et al. Targeted sequencing of genomic repeat regions detects circulating cell-free Echinococcus DNA. PLoS Negl Trop Dis. 2020;14:e0008147.

31. Tamarozzi F, Covini I, Mariconti M, Narra R, Tinelli C, De Silvestri A, et al. Comparison of the diagnostic accuracy of three rapid tests for the serodiagnosis of hepatic cystic echinococcosis in humans. PLoS Negl Trop Dis. 2016;10:e0004444.

32. Ray R, De PK, Karak K. Combined role of Casoni test and indirect haemagglutination test in the diagnosis of hydatid disease. Indian $\mathrm{J}$ Med Microbiol. 2002:20:79-82

33. Siles-Lucas M, Casulli A, Cirilli R, Carmena D. Progress in the pharmacological treatment of human cystic and alveolar echinococcosis: compounds and therapeutic targets. PLoS Negl Trop Dis. 2018:12:e0006422.

34. Sokouti M, Sadeghi R, Pashazadeh S, Abadi S, Sokouti M, Ghojazadeh M, et al. A systematic review and meta-analysis on the treatment of liver hydatid cyst using meta-MUMS tool: comparing PAIR and laparoscopic procedures. Arch Med Sci. 2019;15:284-308.

35. Bayrak M, Altıntas Y. Current approaches in the surgical treatment of liver hydatid disease: single center experience. BMC Surg. 2019;19:95.

36. Hillenbrand A, Gruener B, Kratzer W, Kern P, Graeter T, Barth TF, et al. Impact of safe distance on long-term outcome after surgical therapy of alveolar echinococcosis. World J Surg. 2017;41:1012-8.

37. Zhao ZM, Yin ZZ, Meng Y, Jiang N, Ma ZG, Pan LC, et al. Successful robotic radical resection of hepatic echinococcosis located in posterosuperior liver segments. World J Gastroenterol. 2020;26:2831-8.

38. Goja S, Saha SK, Yadav SK, Tiwari A, Soin AS. Surgical approaches to hepatic hydatidosis ranging from partial cystectomy to liver transplantation. Ann Hepatobiliary Pancreat Surg. 2018;22:208-15.

39. Botsa E, Thanou I, Nikas I, Thanos L. Treatment of hepatic hydatid cyst in a 7-year-old boy using a new type of radiofrequency ablation electrode. Am J Case Rep. 2017:18:953-8.

40. Zhang ZZ, Guo G, Li J, Shi BX, Zhao L, Guo BP, et al. Dog vaccination with EgM proteins against Echinococcus granulosus. Infect Dis poverty. 2018;7:61. 